\title{
Di Gardiner, Tom O'Donaghue \& Marnie O'Neill Constructing the Field of Education as a Liberal Art and as Teacher Preparation at Five Western Australian Universities: An Historical Analysis.
}

Lewiston, Queenston, Lampeter:The Edwin Mellen Press, 2011. 396 pp.

\section{Sharon Anne Cook}

University of Ottawa

We have all heard the questions about the relevance of educational history to our teacher education candidates, and about the low status on campuses of professoriate in Faculties of Education. There has long been a polarization of views about the legitimate goals of Education studies. Should the primary goal be the "high ground of theory" as a route to respectability (2) or an immersion in technical competencies to help the mastery of pedagogy to reach acceptable performance goals? Should Educational studies be in the university community at all, or better placed in a vocationally-oriented institution, like the "Normal Schools" of past ages? If Education is to be part of the university, should the concentration not be on graduate education, rather than teacher preparation?

This is the problematic taken up by the authors of the awkwardly-titled Constructing the Field of Education as a Liberal Art and as Teacher Preparation at Five Western Australian Universities: An Historical Analysis. But don't let the title put you off, because this is an illuminating study of the Australian development of the field through an historical analysis of curriculum change. Furthermore, it poses relevant questions to Canadian policy-makers and historians of education. Against the backdrop of the field's definition in both the United Kingdom and the United States (a particularly useful section of the book), it traces Australia's particularities as they played out at The University of Western Australia, Murdoch University, Curtin University, Edith Cowan University and the University of Notre Dame Australia.

Methodologically, the authors adopt Goodson's approach of the written curriculum as a "social artifact" and as a site of contestation where different interest groups 
struggle for influence and power. Goodson argues that to study curriculum history, both the "preactive" or "rhetorical" curriculum as well as the "interactive" curriculum as mediated by teachers and administrators in the classroom are relevant. Both should be examined over time, the authors argue, to detect the gradual changes against external forces shaping society generally. Needless to say, this is an enormous task, and in fact, difficult to achieve with such a broad research base. This study does not include the interactive element, one we know can call into question neater conclusions based on documentary sources. Nevertheless, it offers a comprehensive documentary analysis of how Education was shaped in these five sites.

To survey the development of Education in Western Australia, the authors invoke a wide range of historical sources including the usual of manuscripts, personal papers, printed materials including course syllabi, meeting minutes, official reports, royal commissions and committees of inquiry and oral histories. Interestingly, visual resources are not utilized or referenced in this otherwise comprehensive range. Secondary sources were used to complete the "external" analysis of broader societal factors, and to contextualize the internal, primary sources.

The result of their investigation is that the structures for the field of Education followed the same general pattern throughout the region. In all cases, universities offered teacher education, in-service professional development, research and graduate studies. However, the orientation of each institution was different in comparison with the others, and over time. Each university drew on traditional partnerships it had inherited from the field, developing a niche in providing graduate or specialist education to a particular level or market segment. Some were more academic than others; some more vocational, but all found a place for themselves in their immediate communities, offering in turn a definable choice to students in Western Australia. The content of the courses offered also varied by institution, extending the choice further.

One of the very interesting issues raised in this study, and as significant for Canadian readers as for Australian, American or British, is the presumed damage to Education by incorporating teacher education into Faculties of Education. The resulting so-called "Cinderella status" of faculty members who suffer from this "imposter syndrome" is parallelled by Education Faculties "at best marginalized and frequently avoided" (317) within the university community. This study found that research was a secondary concern in all five Western Australia universities, with teacher preparation and professional development remaining the primary focus. The authors argue that with the increasing role of the state in certifying teachers, promoting professional issues like reflective practice, professional portfolios, and social issues like race, gender and inclusivity as well as collaborative practices, teacher education and professional doctorates have captured most of these institutions' energies, further impoverishing research funding and production. Rather surprisingly, given the study's impetus, the authors contend that "there is nothing to be gained by attempting to determine whether the study of Education has academic 'status' and that more is to be gained by examining the study of Education in terms of its shifting functions, meanings and purpose within the social and political context" (339). Having set out the many 
political pressures to introduce more and sometimes discordant curriculum at all five of the universities, a process they term "disjointed incrementalism" in one case with a resulting "fragmented" curriculum (333), it appears likely that faculty members involved in such a process would be marginalized and avoided. It is unfortunate that the authors chose not to argue this point more closely.

To the other questions raised, the authors reject a simple binary relationship of graduate or teacher education programs within each university. Similarly, they argue that more than performance goals must be addressed in these programs, and that educational history has much to offer in a nuanced curriculum. As each institution is rooted in its own societal context, each makes different educational contributions to the community it serves. As the twentieth century progressed, full-service institutions offering teacher preparation, professional development and graduate programs were - and still are - needed.

Despite the careful research, the accessible style and energetic tone, the book is marred by very weak editing, resulting in needless repetition and some confusion. With the range of sites investigated, each with its distinctive orientation and local features, summary tables would also have been welcomed to help the reader compare the institutional challenges and responses over time and location. Nevertheless, this study is a welcome contribution to the mounting literature on the place of educational history in Faculties of Education, best practices in Faculties of Education, and the challenges facing the professoriate in these institutions. 